\title{
Developing a Leadership and Diversity Course for an Engineering Manage- ment Program
}

\section{Dr. Sandra L. Furterer, University of Dayton}

Dr. Sandy Furterer is an Associate Professor at the University of Dayton, in the Department of Engineering Management, Systems and Technology. She recently moved from industry as a VP of Process Transformation for Park National Bank in Columbus, Ohio.

Dr. Furterer received her Ph.D. in Industrial Engineering with a specialization in Quality Engineering from the University of Central Florida in 2004. She received an MBA from Xavier University, and a Bachelor and Master of Science in Industrial and Systems Engineering from The Ohio State University.

Dr. Furterer has over 25 years of experience in business process and quality improvements. She is an ASQ Certified Six Sigma Black Belt, a Certified Quality Engineer, an ASQ fellow, and a certified Master Black Belt.

Dr. Furterer is an author or co-author of 4 reference textbooks on Lean Six Sigma, Design for Six Sigma and Lean Systems, including her latest book: Lean Six Sigma Case Studies in the Healthcare Enterprise by Springer publishing in 2014. 


\title{
Developing a Leadership and Diversity Course for an Engineering Management Program
}

\author{
Sandra L. Furterer, Ph.D., MBA \\ Associate Professor of Engineering Management, Systems, and Technology \\ University of Dayton \\ Email: sfurterer1@udayton.edu \\ University of Dayton \\ 300 College Park, \\ Dayton, OH 45469 \\ Phone: (937) 229-2475
}

\begin{abstract}
The purpose of this paper is to describe a new and innovative course in engineering management focusing on leadership and diversity. The paper provides the key learning objectives, instructional strategies, and the success of the course pilot in Spring 2017. The course was piloted with five graduate students in Spring 2017 and piloted again in Spring 2018 with 14 students, 3 undergraduates and 11 graduate students. Assessment of student learning was evaluated through the university's student evaluation of teaching (SET) surveys, through two quiz questions, and through an instructor provided single question survey, asking the students, "How did this course change your life?" Some key findings from the student survey included: "This course creates a vision of our personal growth. It is a complete overall course on life, its characteristics, other managerial skills and last but not the least it encourages you to be a good leader. The most beneficial part that I learned from this course is that I understand how to organize my life and how to make a specific step-by-step plan to achieve my goals. I used to think I could never be a leader. I am not afraid to think about myself as a leader, I started to imagine that I could be a leader now." The value of the course is to develop leaders to excel in a diverse workforce. It provides students with an awareness of the barriers, biases and challenges to diversity in engineering, and provides strategies that can be used to improve satisfaction in the engineering workplace and in academia.
\end{abstract}

Keywords: Engineering management, engineering education, leadership, diversity

Introduction:

Last Spring semester, 2017, an Associate Professor in the Department of Engineering Management, Systems and Technology (EMST), and five engineering students piloted a new Leadership and Diversity course at the University of Dayton. The purpose of the course is to provide students with an understanding of how leadership and diversity combine to enhance creativity, productivity, and innovation. This course provides students with an awareness of the barriers, biases and challenges to diversity in engineering, and provides strategies that can be used to improve satisfaction in the engineering workplace and in academia. The course provides principles and practices that enhance leadership skills for the engineering workplace and provide a personal leadership plan to guide the students' through their life and career. 
This course is important for both men and women to increase awareness, engage everyone in helping to solve the problem, and mold the evolving workplace culture for a more diverse tomorrow. The principles and skills learned can help differentiate students' resumes, especially with companies that embrace a diverse workforce. It provides women and underrepresented minority professionals with strategies to keep them engaged in engineering, both in academia and the field, as well as helping them gain allies that can help them advance in their careers. The course can help those in the majority become allies to moving women forward in their engineering careers.

Literature Review:

Leadership and Diversity Background:

The literature is rich with research on the state of women and underrepresented minorities in academia and the workplace. This section will provide a short summary of the key research that supports the need for a course that will help engineers learn about the state of the research, and understand how they can be better leaders to enhance diversity in academia and the workplace.

We will first describe the following:

- The statistics related to the percentage of women and underrepresented minorities in academia and the workplace.

- The main challenges that women and underrepresented minorities face.

- Strategies that can enhance diversity both in academia and the workplace.

Statistics of women and underrepresented minorities in academia and the workplace:

Although the numbers of women and underrepresented minorities has increased in academia and the workplace, the relative percentages have stayed relatively constant over the last 30 years. While women represent about $50 \%$ of the workforce, women made up only about $27 \%$ of the STEM professionals, in 2008 . Additionally, women made up only about $12 \%$ of the workforce in engineering, in 2013 (McCauley-Bush). In a Leanin.org and McKinsey study, on average, women are promoted and hired at lower rates than men, so far fewer women become senior leaders. At more senior levels, we see women shift from line to staff roles, so very few end up on the path to becoming CEO, and women remain underrepresented in the corporate pipeline. Women are $46 \%$ of the entry level workers, yet make up only $19 \%$ of the C-suite, at the highest levels of executive leadership (Leanin.org, 2016). Women made up only $1 \%$ of the engineering workforce in 1960, 9\% in 1990 and 12\% in 2013 (Corbett and Hill, 2015). The percent of bachelor's degrees awarded to women engineers has also remained relatively constant over the last 30 years or so. In 1970 only $1 \%$ of the bachelor's degrees awarded were to women engineers, in 2015 it had risen to 19.9\%, as shown in Figure 1 (Corbett and Hill, 2015), (Yoder, 2018). 


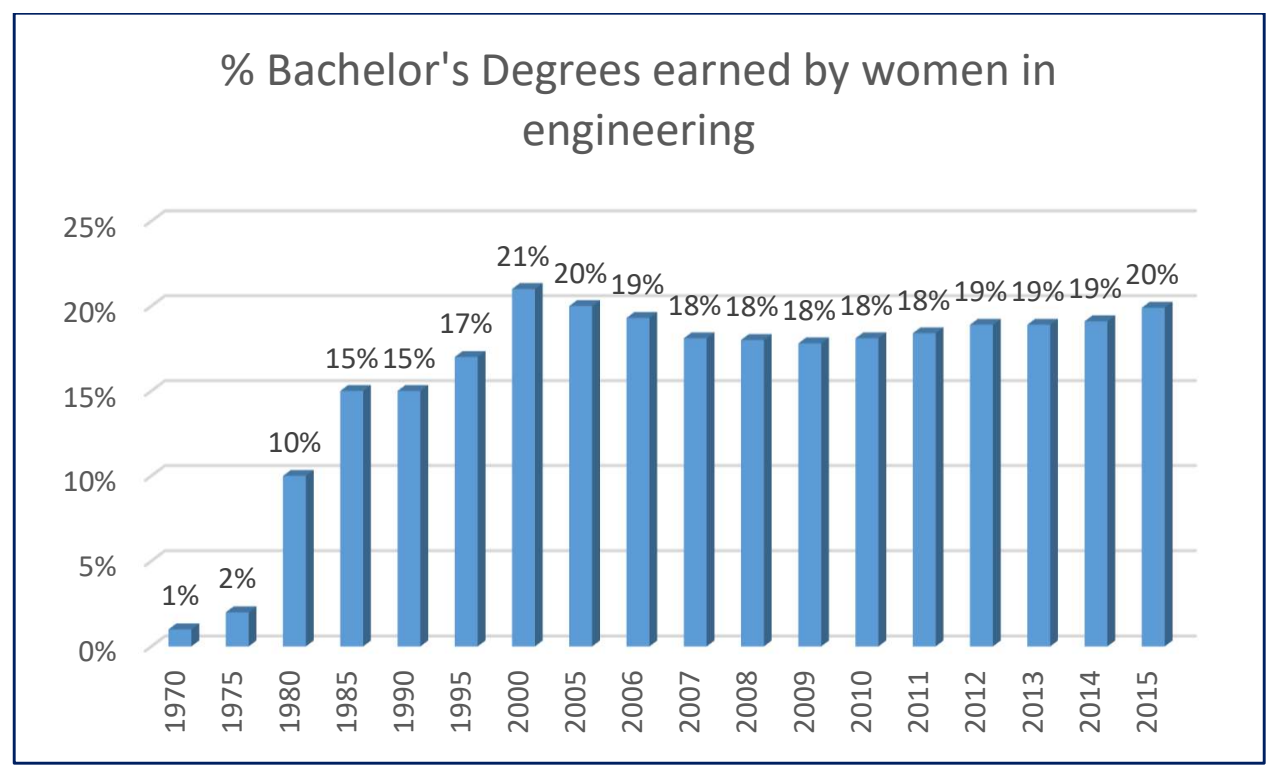

Figure 1 Percentage of women being awarded bachelor's degrees in Engineering by year

The main challenges that women and underrepresented minorities face in the workplace are summarized in this list: (Williams and Hall, 2014)

- Early choices not to pursue math and science careers

- Isolation of STEM careers in the workplace \& academia

- Women express a preference for "meaningful" work, which isn't always communicated by engineering programs

- Stereotype threat: math, science (as early as 1 st grade)

- Gender bias: hiring, promotion, evaluations

- Explicit gender bias is declining, implicit or unconscious gender bias remains widespread

There are 4 key patterns of gender bias and stereotyping that impede women's progress in the workplace. A stereotype "is an oversimplified and/or unfair belief or idea that groups of people have particular characteristics or that all people in a group are the same". (Teaching Tolerance, 2017). A gender stereotype is an oversimplified and/or unfair belief or idea that women or men as a group have particular characteristics or that all women or men are the same within their own group. "Stereotypes are cognitive shortcuts or generalizations that we use to make sense of our complex social world. Gender stereotypes are widely shared within cultures. Extensive research has shown that women and men are more similar than different. Gender stereotypes can cause women to be overlooked for top jobs." (McCauley, 2012). Stereotypes are unconscious, where we don't even know that we are thinking in this way. These unconscious biases have been found to influence hiring decisions, job assignments, promotions, performance reviews, training opportunities, policies, marketing campaigns, customer service and the selection of leaders (Heltzel, 2016).

Gender stereotypes tend to place greater social value on men and evaluate men's competence as greater than women's. These stereotypes are very powerful and can be difficult to override (Corbett and Hill, 2015). An example of a gender stereotype is "When women emphasize their competent characteristics and effectiveness at work, they often experience backlash for violating 
the gender stereotype that women are warm, and they are seen as less likeable than men who emphasize the same behaviors, especially in male dominated fields" (Phelan et all., 2008; Rudman \& Phelan, 2008; Heilman, Wallent et al., 2004). On the other hand, women seen as warm but not competent are less likely to be respected and more likely to be pitied and socially neglected in the workplace (Fiske, 2012; Cuddy et al., 2007).

Following are just a few findings from the rich body of research on gender stereotypes and bias that impact women in the workplace (Corbett and Hill, 2015).

- Although men are stereotypically thought of as competent in many domains, women are stereotypically considered to be warm.

- Managers reward male employees more generously than equally qualified female employees.

- Biased behavior or discrimination today most often results from "in-group" favoritism, or giving preferential treatment to others with whom we identify in some way, as opposed to negative treatment of "out-group" members of groups with whom we don't identify.

- Sex segregation is an especially resilient form of inequality because people so ardently believe in, enact, and celebrate cultural stereotypes about gender differences.

- In the overall population of full time workers, a typical woman is paid 78 cents for every dollar paid to a typical man (U.S. Census Bureau, 2014b).

Although explicit gender bias is declining, implicit or unconscious gender bias remains widespread (Corbett and Hill, 2015). There are four common implicit biases as follows:

- Prove-it-again

- The prove-it-again bias requires women to prove themselves over and over again. This requires women and people of color to work much harder than men to be seen as equally competent (Corbett and Hill, 2015).

- Tightrope:

○ The tightrope bias requires women to "walk a tightrope" to display masculine qualities identified with leadership, while maintaining their femininity. Women wrestle with being seen as either nice or competent, but not both. If a women is seen as competent, many times they are perceived as too aggressive. (Cuddy, Fiske, \& Glicke, 2004; Fiske, Xu, \& Duddy, 1999; Heilman, 2001; Prentice \& Carranza, 2002; Brescoll \& Uhlmann, 2008; Rudman, 1998).

- Maternal wall:

o The maternal wall is a barrier for women with children and those who have never had children. Women with children are seen as either not committed, because they have children and may leave work early to care for them, or seen as a poor mother, because they are too dedicated to their job. Additionally, women who don't have children can be seen as not natural, because they are not meeting their perceived gender role to bear children. They also may be expected to take up the slack of women who have children when the mothers need to care for their children. (Corbett and Hill, 2015)

- Tug of war:

- Tug of war is the competition that can exist between the few or 'token' women in the workplace. There is the belief that there are not enough key assignments and 
promotions to go around for the few women in the workplace, so they tend to compete with each other, instead of support each other. Additionally, there is a tendency for women who have suffered through adversity in the workforce that believe that other women should also suffer, and therefore do not provide guidance or help through mentoring, networking and coaching. (Kanter, 1977a, 1977b).

Strategies that can enhance diversity in academia and the workplace.

There are many strategies that can be applied in both academia and the workplace. There are many suggested strategies, but little research that supports what works best. The following strategies are suggested in the literature to improve diversity of women and underrepresented minorities in the workplace and in academia: (Corbett and Hill, 2015)

- Reduce the negative effects of gender bias in hiring, evaluations and promotion decisions.

- Make job qualifications clear and apply them evenly to all candidates.

- Base hiring decisions on objective past performance information when possible.

- Purposely remove gender information from evaluation scenarios when possible.

- Allow sufficient time to make in-depth and individualized evaluations of applicants.

- Survey employees to assess the level of gender bias within your organization.

- Hold managers and recruiters accountable for their hiring and promotion decisions.

- Encourage a sense of belonging for all employees.

- Encourage a supportive, friendly, and respectful environment.

- Root out uncivil and undermining behaviors.

$\circ$ Increase the number of women at all levels of management.

- Provide opportunities for women to develop a support network of other technical women.

- Formally recognize necessary nontechnical work such as working well with others and mentoring - work that is not male-stereotyped — along with technical work.

- Be proactive and vocal about management's commitment to increasing the representation of technical women in your organization.

- Facilitate opportunities for employees to work on projects or issues that are socially relevant

- Men working in engineering and computing to serve as role models.

- Emphasize ethical and social issues when teaching engineering and computing.

- Encourage a supportive environment in the classroom and in the program.

- Encourage and assist early contact between students and professionals.

- Emphasize the wide variety of expertise necessary to be successful as an engineer or computing professional.

- Highlight as early as possible the different facets that make up engineering and computing.

Methodology and Educational Learning Strategies:

This course came out of a passion by the instructor to enhance leadership and diversity in both academia and the workplace. The instructor attended a Society of Women Engineers (SWE) conference in 2016 and became inspired to prepare engineers for embracing diversity and 
understanding the challenges that women and underrepresented minorities face in the workplace. The instructor had been a woman engineer in industry and in academia for many years, and had experienced many of the same challenges discussed in the research literature. The course development was highly supported by the Dean of the School of Engineering (SoE), the Engineering Management, Systems and Technology Department chair, the Engineering Management Graduate program coordinator, the SoE's Diversity and Inclusion program, and the other department chairs within the School of Engineering. The instructor developed and piloted the course in the Spring 2017 semester. The first time that the course was piloted in 2017, it was run as a graduate course. In Spring 2018, it was piloted as a course for both undergraduates and graduate students. A KEEN grant provided a stipend for the faculty member to incorporate innovation and leadership material into the course for undergraduate students. The personal leadership plan was formalized as part of this grant. The main difference for the undergraduate students was that they were not required to develop a research report.

For the new leadership and diversity course the course goals and student learning outcomes are:

Upon successful completion of the course the student should:

1) Explain the implicit biases discussed in the literature that women and underrepresented minorities in engineering face in the workplace, providing examples of how they may be experienced.

2) Evaluate the research on women and underrepresented minorities in engineering issues, barriers and challenges.

3) Design and practice strategies for helping women and minorities stay engaged in engineering in the workplace.

4) Design and practice strategies for how colleagues can mentor and engage women and underrepresented minorities in the engineering workplace.

5) Explain cultural aspects of women and minorities in other countries.

6) Enhance the students' personal leadership skills.

The instructor incorporated the following instructional strategies for the course.

- Information providing: Lectures and a course website that provides course materials. Lectures are kept to a minimum, as the student is expected to review the research articles, PowerPoint slides lecture notes, and book material prior to the class session.

- Inquiry-oriented reflection-based active learning exercises: Discussions questions are used throughout the class session to discuss the topics covered. The students work in pairs or teams to discuss the material and reflection questions, and then present their ideas to the class.

- Cooperative: The students create their own course module consisting of review of a research article and material related to their chosen topic related to any of the topics covered within the course. The students present the material to the class, and encourage discussion by generating discussion topics.

- Master-based: Quizzes assess the students' mastery of the course material throughout the course. 
- Creative-inducing: The graduate students will extend the course module topic in a research paper, where they further research the literature, summarize their topic, and propose a research topic in the subject area.

The course topics, organized by the three main areas of awareness, strategies and cultural aspects are shown in Figure 2.

\begin{tabular}{|c|c|c|}
\hline Awareness & Strategies & Cultural Aspects \\
\hline $\begin{array}{l}\text { - State and statistics of women and } \\
\text { underrepresented minorities in } \\
\text { Engineering } \\
\text { - Barriers and challenges for } \\
\text { women and minorities in: higher } \\
\text { education, academic positions, } \\
\text { workplace } \\
\text { - Understanding the importance of } \\
\text { leadership and innovation } \\
\text { - Implicit Biases } \\
\text { - Double Jeopardy, women and } \\
\text { diversity of race and ethnicity }\end{array}$ & $\begin{array}{l}\text { - Strategies for women's and } \\
\text { minorities' engagement in } \\
\text { Engineering in higher education } \\
\text { - Strategies for women's and } \\
\text { minorities engagement in the } \\
\text { workplace } \\
\text { - Strategies for engagement, } \\
\text { overcome biases and challenges }\end{array}$ & $\begin{array}{l}\text { - Cultural aspects of } \\
\text { diversity } \\
\text { - Winners don't quit } \\
\text { - Gender STEM stereotypes } \\
\text { - Real-world stories } \\
\text { - Outreach in organizations: } \\
\text { SWE, AAUW } \\
\text { - Changing organizational } \\
\text { cultures: academia and } \\
\text { industry } \\
\text { - Research areas of women } \\
\text { and minorities in } \\
\text { engineering } \\
\text { - Strategies for cultural } \\
\text { change }\end{array}$ \\
\hline
\end{tabular}

Figure 2: Course Topics

In addition to several research articles, we also use Pamela McCauley Bush's book, Transforming Your STEM Career Through Leadership and Innovation, 1st Edition, 2012.

Since this is both an undergraduate and a graduate course, the course needs to be mindful of ABET student outcomes, currently outcomes (a) through $(\mathrm{k})$ in the engineering accreditation criteria. The following ABET student outcomes for engineering program accreditation can be assessed for this course (ABET Engineering, 2017):

(d) an ability to function on multidisciplinary teams

(f) an understanding of professional and ethical responsibility

(g) an ability to communicate effectively

(j) a knowledge of contemporary issues

The following ABET student outcomes for engineering technology program accreditation can be assessed for this course (ABET Engineering Technology, 2017)

(d) an ability to function effectively as a member of a technical team;

(f) an ability to apply written, oral, and graphical communication in both technical and nontechnical environments; and an ability to identify and use appropriate technical literature; (h) an understanding of and a commitment to address professional and ethical responsibilities, including a respect for diversity; 
Course Assessments and Assignments:

The course assessments and assignments are shown in Figure 3.

\begin{tabular}{|l|c|}
\hline \multicolumn{1}{|c|}{ Element } & Points \\
\hline Student Bio and Presentation & 25 \\
\hline Notes journal for in-class discussions & 75 \\
\hline Quizzes 4 (50 points each) & 200 \\
\hline Course module (team-based) & 200 \\
\hline Research paper (Graduate students only) & 300 \\
\hline Personal leadership plan & 200 \\
\hline Total Points & $\mathbf{1 0 0 0}$ \\
\hline
\end{tabular}

Figure 3: Course assessments and assignments

Student Bio and Presentation:

Each student must complete the requested PowerPoint slide describing their background and experience. Each student will present their bio and introduce themselves to the students during our first class session.

Notes journal for in-class discussions:

The class time will be an opportunity for students and the instructor to discuss and share their views on the course material. The students should read the materials and readings in advance of the class so that they are prepared to participate. After each class period, the student should make hand written notes in their class journal (a notebook or theme book) on key discussion points, learnings and interesting topics that intrigued the student with their reflections, feedback and comments. The journal will be reviewed by the instructor periodically throughout the semester.

Quizzes:

We will have 4 quizzes throughout the semester. These quizzes will be on specific dates shown on the course schedule. The students will take the quizzes through the course website.

Course Module:

Course Module Development Project and Presentation: Student teams will produce a complete Learning Module for their assigned topic.

Learning Modules will consist of a:

- Power Point presentation

- At least one relevant article from the literature on the topic area

- Discussion of assigned materials and article

- Discussion questions with student discussion, and 
- Presentation of the PowerPoint presentation in the class.

The students will submit all materials via the course module assignment one week prior to the class presentation. The instructor will upload the material onto the class web site so that the other students can review the material. The student(s) will then lead the class through a lecture/Q\&A session during the assigned class time. They will also moderate the discussion questions during the presentation for their module. Each student will read the assigned readings, and then select at least one topic. They will then research the academic or trade journals, via the Library databases, and find an article that applies or researches that topic. The course module will discuss the article including the topic, hypothesis, framework, and summary of the research, the findings and conclusions and future research.

\section{Research Project}

Research the scholarly and trade literature to identify articles related to research on women or underrepresented minorities in engineering and science. This assignment is intended to extend your course module research that you have collected and developed into a course module. You will use the articles already collected, and add additional articles as necessary to build a cohesive set of research articles for your topic. You will propose a research study that extends this existing research for this research paper.

Required Research Project Elements:

- Description of the purpose of the research paper.

- Proposed research methodology.

- Description of the existing literature. What are the key findings and state of the literature related to your research topic? What is the research gap that you are trying to close?

- Description of your proposed research, its goals, your hypothesis and expectations.

- Data that would be collected, expected tools and analysis that would be applied, and your intended results.

- Expected findings and conclusions.

- Areas for future research after your study would be complete.

- Your assessment of impact of the research to the research body of knowledge related to your research topic.

Personal Leadership Plan

The personal leadership plan will be developed throughout the semester based on the course textbook active learning exercises during the class sessions. The personal leadership plan grading checklist is shown in Figure 4.

Personal Leadership Plan

\begin{tabular}{|l|c|c|c|}
\hline \multicolumn{1}{|c|}{ Item } & $\begin{array}{c}\text { Points } \\
\text { Available }\end{array}$ & $\begin{array}{c}\text { Points } \\
\text { Received }\end{array}$ & Comments \\
\hline 1) Personal mission statement & $\mathbf{1 0}$ & & \\
\hline 2) Strength Identification Log & $\mathbf{1 0}$ & & \\
\hline 3) List of Mentors & $\mathbf{1 0}$ & & \\
\hline 4) Mentoring focus areas & $\mathbf{1 0}$ & & \\
\hline
\end{tabular}




\begin{tabular}{|l|c|l|l|}
\hline 5) Mentoring Resources & $\mathbf{1 0}$ & & \\
\hline $\begin{array}{l}\text { 6) Biblio - Mentor - Collage (BMEC) } \\
\text { Overview }\end{array}$ & $\mathbf{1 0}$ & & \\
\hline 7) Networking Opportunities & $\mathbf{1 5}$ & & \\
\hline 8) Leadership Questionnaire & $\mathbf{1 0}$ & & \\
\hline 9) Leadership Test & $\mathbf{1 0}$ & & \\
\hline 10) What are your leadership goals? & $\mathbf{1 0}$ & & \\
\hline $\begin{array}{l}\text { 11) Develop your personal career vision } \\
\text { statement }\end{array}$ & $\mathbf{1 5}$ & & \\
\hline 12) Vision Statement & $\mathbf{1 0}$ & & \\
\hline $\begin{array}{l}\text { 13) Enhancing your personal career } \\
\text { mission statement }\end{array}$ & $\mathbf{1 0}$ & & \\
\hline $\begin{array}{l}\text { 14) Leadership Development Assessment } \\
\text { Survey }\end{array}$ & $\mathbf{1 0}$ & & \\
\hline 15) Individual Development plan & $\mathbf{1 5}$ & & \\
\hline 16) Innovation Plan & $\mathbf{1 5}$ & & \\
\hline 17) Commitment to the woman team quiz & $\mathbf{1 0}$ & & \\
\hline 18) Goals by Area & $\mathbf{1 0}$ & & \\
\hline Total Points & $\mathbf{2 0 0}$ & & \\
\hline
\end{tabular}

Figure 4: Personal Leadership Plan Grading Checklist

Key success factors for the course:

The following key success factors are important to incorporate into the course.

1) Develop class rules of engagement to ensure confidentiality, open, honest and creative idea sharing. The Spring 2018 rules of engagement are shown below.

- Speak freely

- Be open and honest

- Look at everyone for their individuality and differences

- Look at the individual personality

- Recognizing the tangible value in the intangible

- Confidentiality - what is said here, stays here

- Everyone should have a voice and participate

- Think outside of stereotypes

- Be humble

- Respect for everyone

2) On-campus, in person classroom sessions. The EMST graduate program offers most of their courses as a combined on-campus sessions with live and recorded simulcasts. However, due to the sensitive nature of the course topics, we decided to only have on-campus in person classroom sessions, so that the live participation, and lack of recording encourages open and honest discussions.

3) Sensitivity and no-blaming by the instructor or students. This is probably one of the most critical success factors for the course. No students should feel disengaged, disenfranchised or to blame for the state of diversity. It is important that everyone feels engaged, and open to share their ideas, no matter their gender, race, ethnicity, culture, or opinions. 
4) Class sessions that are no less than 75 minutes, to ensure enough discussion time within the class sessions.

Instructor Assessment of Learning:

There were two assessments used to assess the course. The first was the Student Evaluation of Teaching (SET) results, and the other was an instructor provided quiz question that the students completed.

Student Evaluation of Teaching (SET) results:

The Student Evaluation of Teaching (SET) Results demonstrate that the students rated the course highly, as shown in Figure 5. The following questions were asked in the SET survey.

Q1: The instructor seemed organized.

Q2: I knew what I was expected to accomplish in this course.

Q3: The instructor presented the subject matter clearly.

Q4: The instructor created an environment that supported my learning.

Q5: The instructor generated a genuine interest in my success.

Q6: The feedback I received from the instructor improved my learning.

Q7: This course stimulated my interest in the subject.

Q8: This course increased my understanding of the subject.

Q9: I learned a great deal from this course.

Q10: I would recommend this course to other students.

Q11: I would recommend this instructor to other students.

A Likert agreement rating scale was used, from 1 - Strongly Disagree, to 5- Strongly Agree.

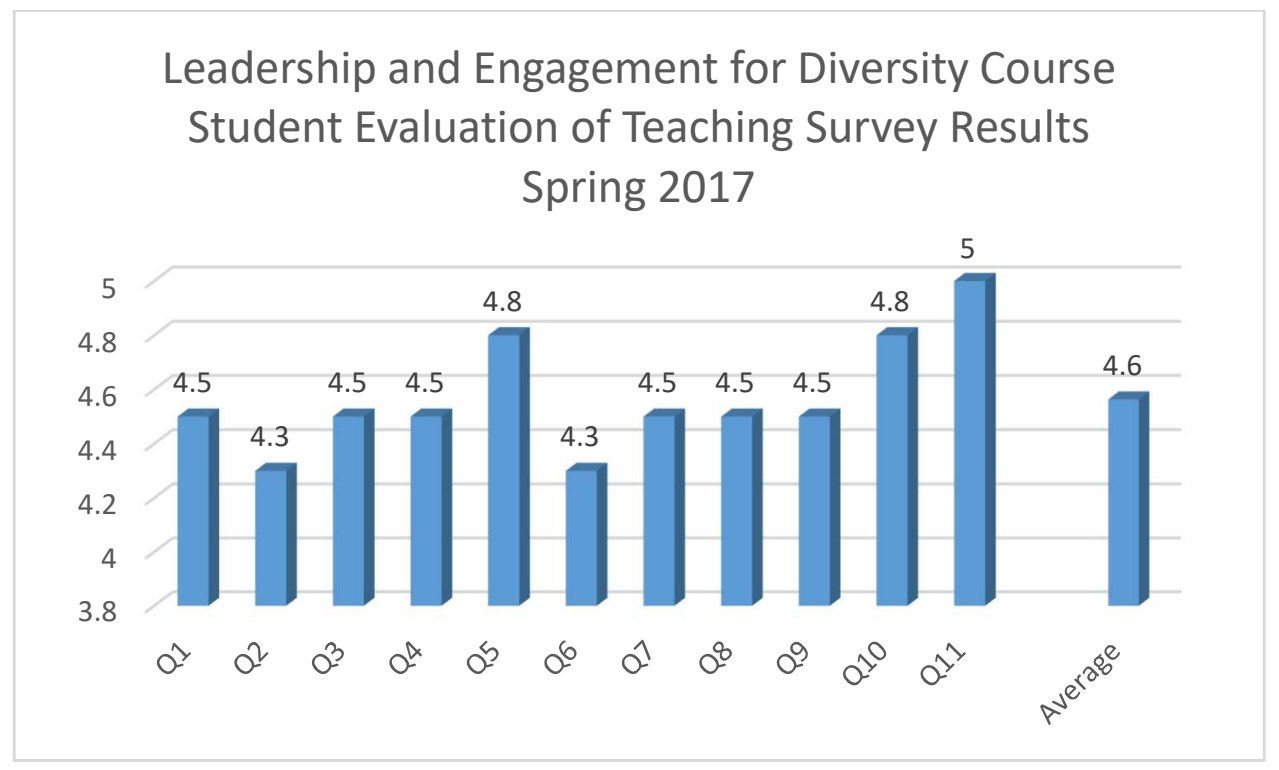

Figure 5 Leadership and Engagement for Diversity Course Student Evaluation of Teaching Survey Results Spring 2017 
Instructor provided quiz question:

How did this course change your life?

The students completed their response to the question, "How did this course change your life?" The Spring 2017 students provided excellent feedback on the course, as follows:

"This course creates a vision of our personal growth. It is a complete overall course on life, its characteristics, other managerial skills and last but not the least it encourages you to be a good leader."

"The most beneficial part that I learned from this course is that I understand how to organize my life and how to make a specific step-by-step plan to achieve my goals."

"I used to think I could never be a leader. I am not afraid to think about myself as a leader, I started to imagine that I could be a leader now."

"The group activities and quizzes made me think about my career goals. It gave me time to think about myself, my strengths and weaknesses that I have. As this class was completely interactive, I am now confident that I can answer any question asked spontaneously. I learned how important it is to raise my voice and network. I also learned how to negotiate for what I deserve and I have already started practicing it in real life. The professor has designed this course so well that everything I learnt was step by step. This course also taught me how to balance work and family through time management. "

"The course taught us a lot of tools and strategies that I could use to engage women in the STEM field."

Assessment of student learning by course quiz questions:

The instructor assessed student learning by course quiz questions in the Spring 2017 semester. Two examples to assess the student learning regarding 1) understanding stereotypes and 2) ideas to implement in the workplace or academia to increase the numbers of women in engineering were performed.

The first quiz question asked the students to describe stereotype threat: what it is, and how it exhibits itself in the workplace or academia. Then the students were asked to describe some ideas for reducing stereotype threat either in the workplace or academia. The average grade was $84 \%$ for the 5 students for quiz question one ( 4.2 out of 5 points).

The second quiz question asked the students to describe five ideas that were discussed in the literature that could increase the numbers of women in engineering and /or computing. For each idea, give examples of how you might implement the idea in a workplace or academia, and whether you think the idea will work to increase the numbers of women in engineering and computing. For this question, the average grade was $100 \%$ (10 out of 10 points).

The student assessment of learning using the quiz questions was effective in assessing that the students were learning the material related to stereotypes and strategies for improving the numbers of women in engineering. 


\section{Reflection and Conclusions:}

The course exceeded the instructor's expectations. There is such a richness of research on the topic of leadership and diversity. The students were open, honest and innovative in sharing their ideas and opinions on the topics. The first cohort of students included 2 females from India, 1 Chinese male, and 2 men from Saudi Arabia. Everyone learned a great deal about the subject matter and other cultures, and the instructor believes that it helped all of us to be more openminded, and less-biased in the future. The learning strategies and course assignments worked extremely well for the type of course topics. Allowing the students to explore the current literature and find new research findings was invaluable, as was enabling them to create and deliver their own course module. The research paper where the students designed their own research study was also valuable for the students. In Figure 6, two questions that had lower ratings were question 2, "I knew what I was expected to accomplish in this course", and question 6, "The feedback I received from the instructor improved my learning." A reflection as to why these questions received a lower rating could be related to this being a new course. The instructor may want to place more emphasis on providing clear expectations for the course assignments and enhancing the grading rubrics and feedback provided on the grading. The course was approved during the Spring 2018 semester by the department as an elective course to be taught at the undergraduate and graduate levels. It is currently going through the university curriculum committees for further approval.

\section{Future Work:}

The instructor has incorporated topics related to leadership and innovation to further enhance the course through a KEEN grant. The instructor will continue to enhance the course based on the course this Spring 2018. The course has been approved as an elective within the School of Engineering for all but one department, and is making its way through the course curriculum review process.

\section{References:}

2018-2019 Criteria for Accrediting Engineering Programs, ABET Engineering Accreditation Commission, Baltimore, MD, abet.org, 2017

2018-2019 Criteria for Accrediting Engineering Technology Programs, ABET Engineering Technology Accreditation Commission, Baltimore, MD, abet.org, 2017

Brescoll, V. L., Uhlmann, E. L., Moss-Racusin, C., \& Sarnell, L. (2012). Masculinity, status, and subordination: Why working for a gender stereotype violator causes men to lose status. Journal of Experimental Social Psychology, 48(1), 354-57. doi:10.1016/j.jesp.2011.06.005.

Corbett and Hill, Solving the Equality The Variables for Women's Success in Engineering and Computing AAUW, 2015.

Cuddy, A. J. C., Fiske, S. T., \& Glick, P. (2007). The BIAS map: Behaviors from intergroup affect and stereotypes. Journal of Personality and Social Psychology, 92(4), 631-48. doi:10.1037/00223514.92.4.631. 
Fiske, S. T. (2012). Managing ambivalent prejudices: Smart but-cold and warm-but-dumb stereotypes. Annals of the American Academy of Political and Social Science, 639(1), 33-48. doi: $10.1177 / 0002716211418444$.

Heilman, M. E. (2001). Description and prescription: How gender stereo types prevent women's ascent up the organizational ladder. Journal of Social Issues, 57(4), 657-74. doi:10.1111/0022-4537.00234.

Heilman, M. E., Wallen, A. S., Fuchs, D., \& Tamkins, M. M. (2004). Penalties for success: Reaction to women who succeed in male gender-typed tasks. Journal of Applied Psychology, 89(3), 416-27.

Heltzel, B., Workplace bias felt in 'a thousand cuts'. Westchester County Business Journal, MAY 9, 2016 | VOL. 52, No. 19

Kastner, Westman \& Wilkins, Respondent's Position Statement, Page 2, June 15, 2017.

McCauley-Bush, P., Transforming Your STEM Career Through Leadership and Innovation, 1st Edition. Academic Press, 2012.

No author, Teaching Tolerance, What are Gender Stereotypes?, https://www.tolerance.org/classroomresources/tolerance-lessons/what-are-gender-stereotypes, accessed 1/23/2018.

Phelan, J. E., Moss-Racusin, C. A., \& Rudman, L. A. (2008). Competent yet out in the cold: Shifting criteria for hiring reflect backlash toward agentic women. Psychology of Women Quarterly, 32(4), 40613. doi:10.1111/j.1471-6402.2008.00454.x.

Prentice, D. A., \& Carranza, E. (2002). What women and men should be, shouldn't be, are allowed to be, and don't have to be: The contents of prescriptive gender stereotypes. Psychology of Women Quarterly, 26(4), 269-81. doi:10.1111/1471-6402.t01-1-00066.

Rudman, L. A., \& Phelan, J. E. (2008). Backlash effects for disconfirming gender stereotypes in organizations. Research in Organizational Behavior, 28, 61-79. doi:10.1016/j. riob.2008.04.003.

U.S. Census Bureau, https://www.census.gov/data.html, 2014b

Williams and Hall, Double Jeopardy? Gender Bias Against Women of Color in Science, 2014.

Women in the Workplace 2016, LeanIn.org and McKinsey \& Company, LeanIn.Org, 2016.

Yoder, B., Engineering by the Numbers, ASEE.org/colleges, downloaded 3/19/2018. 